\title{
Risk Assessment of Benzene Homologues in Correction Fluids
}

\author{
He Shujuan, Zhao Qichao, Liu Yan, Chen Chang \\ China National Center for Quality Supervision and Test of Environmental Protection Products
}

Keywords: correction fluids, toluene, xylene, risk assessment, exposure value

\begin{abstract}
The research is carried out potential health assessment of benzene homologues exposure in correction fluids to primary and secondary students. 10 brands of correction fluids including two hundreds representative and typical samples were collected in Hebei province of China for detecting contents of toluene and xylene (3 isomers). And then, it was established risk assessment model on the basis of the contents of benzene homologues and physiological characteristic of primary and secondary students. The results is indicated that it was checked out xylene isomers residual solvents from 3 brands of samples, the average detection rate is $30 \%$, and the target hazard quotients (THQ) is greater than 1. Because correction fluids was caused exposure health risk by respiration and ingestion, it suggested that relevant departments was needed to formulate and revise the national compulsory standards for defining limited values of toluene and xylene in correction fluids.
\end{abstract}

Correction fluids was one of the most commonly used stationery by primary and secondary students, if there were some improper behaviors in use, it was increased the potential health risk as students' behavior was not completely controllable. At present, there were 3 kinds of solvents in correction fluids production process - trichloroethane, hexahydrotoluene and hexamethylene, but a few illegal businessmen use benzene homologues for costs reduction which had better dissolving property $^{[1]}$. And these correction fluids producers were tend to use toluene and xylene instead of benzene, because there was strict limited for content of benzene in China national and industry standards such as GB 21027-2007 ${ }^{[2]}$, QB/T 2655 ${ }^{[3]}$ and QB/T 4154 $4^{[4]}$, etc. The organic solvents vaporization in correction fluids was caused eye, mucosa and skin stimulation, and even worse, it would cause organ damage. The study was detected contents of benzene homologues in correction fluids samples by Gas chromatography (GC), and carried out exposure risk assessment to benefit effective supervision by providing scientific basis.

\section{Experiment}

\subsection{Instruments and materials}

Instrument: Agilent 7890B Gas chromatography (GC) with liquid injector and FID detector.

GC condition: Chromatographic column was HP-Innowax $(60 \mathrm{~m} \times 0.25 \mathrm{~m} \times 0.5 \mu \mathrm{m})$. Injection port temperature was 230 Celsius degrees. Carrier gases was nitrogen (Purity $\geq 99.999 \%$ ). Column flow rate was $1 \mathrm{~mL} / \mathrm{min}$. Injection valve was $1 \mathrm{~mL}$. Sample injection method was split stream (split ratio: 10:1).

Chromatographic column heating procedure: initial temperature was 60 Celsius degrees and hold $5 \mathrm{~min}$, heating up to 120 Celsius degrees by 5 Celsius degrees per minutes and then heated up to 150 Celsius degrees by 15 Celsius degrees per minutes. Finally, it heated up to 240 Celsius degrees by 20 Celsius degrees per minutes and hold 2 min.

Standard substance and preparation: take a given volume of toluene, o-xylene, m-xylene, p-xylene (Purity $\geq 99.0 \%$ ) diluting with ethyl acetate to $1000 \mathrm{~mL}$ standard stock solution, respectively. And then, dilute standard stock solution to standard solution series in turn.

Samples: 10 brands of correction fluids including 200 representative and typical samples which collected in Hebei province of China. 


\subsection{Method}

According to GB 21027-2007 <Request in common use of security for student's articles> appendix $C$ (determination of toluene and xylene in adhesive gas chromatography), the study is detected content of toluene and xylene.

\section{Results and discussion}

\subsection{Test results}

The research was detected the content of toluene and xylene of 10 brands of 200 samples, respectively. In the 200 samples, 3 brands of correction fluids were detected xylene (3 isomers), the average detection rate of o-xylene, m-xylene and p-xylene was $30 \%$. All of samples was not detected out toluene. In GB 21027-2007, the content of benzene of correction fluids production was not to exceed $10 \mathrm{mg} / \mathrm{kg}$, but there was not stipulated content of toluene and xylene. However, in GB 21027-201X exposure draft, the limited content of toluene + xylene was $40 \mathrm{mg} / \mathrm{kg}$, it indicated the xylene content of 3 brands correction fluids were exceed limits. The result was shown in Tab.1.

Tab.1 The results of benzene homologues in correction fluids

\begin{tabular}{c|cccc} 
Brands & Toluene $(g / \mathrm{kg})$ & o-xylene $(g / \mathrm{kg})$ & m-xylene $(\mathrm{g} / \mathrm{kg})$ & $p$-xylene $(\mathrm{g} / \mathrm{kg})$ \\
\hline 1 & ND & 4.37 & 9.10 & 4.94 \\
2 & ND & 4.24 & 9.98 & 6.03 \\
3 & ND & 11.8 & 23.69 & 12.48 \\
4 & ND & $<0.02$ & $<0.02$ & $<0.02$ \\
5 & ND & $<0.02$ & $<0.02$ & $<0.02$ \\
6 & ND & ND & ND & ND \\
7 & ND & ND & ND & ND \\
8 & ND & ND & ND & ND \\
9 & ND & ND & ND & ND \\
10 & ND & ND & ND & ND \\
11 & ND & ND & ND & ND \\
\hline \multirow{2}{*}{ Remarks } & ND-Not Detected; Method Detection Limit of toluene and xylene was & & &
\end{tabular}

Because the main users of correction fluids were students, there was some improper behaviors in daily use, unavoidable. Thus, it increased the safety risk in the use of correction fluids, the research was carried out the health risk assessment by exposure risk assessment model.

\subsection{Risk assessment model}

\subsubsection{The calculation of exposure does}

Toluene and xylene were aromatic organic compounds which was most common of organic solvent. These volatile organic solvent was entered human body mainly through respiration exposure. According to <Exposure Factor Handbook of Chinese Population (Children) $>^{[5]}$, the exposure does of human body exposure by respiratory tract was calculated by Eq.1.

$$
\mathrm{ADD}=\frac{C \times I R \times E F \times E D}{B W \times A T}
$$

Where:

ADD is average daily exposure dose of hazardous substances, $\mathrm{mg} /(\mathrm{kg} \cdot \mathrm{d}) \quad$;

$\mathrm{C}$ is concentration of hazardous substances, $\mathrm{mg} / \mathrm{m}^{3}$;

IR is respiration rate per unit time, $\mathrm{m}^{3} / \mathrm{d}$;

$E F$ is exposure frequency, $d / a$;

ED is exposure duration, a;

$\mathrm{BW}$ is body weight, kg;

AT is average exposure time (Non-cancerogen is $30 * 365=10905$ ), $d$. 
From the point of view of the sample quality risk assessment, there was more valuable for daily limit intake of sample hazardous substances. Therefore, average exposure time $\frac{E F \times E D}{A T}$ in Eq.1 was developed to average daily exposure time $(\mathrm{t})$, moreover, the mass concentration was calculated with $C_{i}(\mathrm{mg} / \mathrm{kg})$, production usage mass $m(\mathrm{~kg})$ and volume of compounds $V\left(\mathrm{~m}^{3}\right)$ by $\frac{C_{i} \times m}{V}$. That is, the Eq.1 was converted to Eq.2 to calculation.

$$
\mathrm{ADD}=\frac{C_{i} \times m \times I R_{i} \times t}{V \times B W}
$$

Where:

ADD is average daily exposure dose of hazardous substances, $\mathrm{mg} /(\mathrm{kg} \cdot \mathrm{d}) \quad$;

$C_{i}$ is mass concentration of hazardous substances, $\mathrm{mg} / \mathrm{kg}$;

IR is respiration rate per unit time, $\mathrm{m}^{3} / \mathrm{h}$;

$\mathrm{t}$ is exposure time, $\mathrm{h} / \mathrm{d}$;

$\mathrm{V}$ is volume of hazardous substances, $\mathrm{m}^{3}$;

BW is body weight, kg;

The reference dose of xylene (RfD) was as Tab.2 which was consult in the data of integrated risk information system in U.S. EPA ${ }^{[6]}$.

Tab.2 Reference dose of xylene

\begin{tabular}{|c|c|}
\hline Compounds & $\begin{array}{r}\text { reference dose of xylene }(\mathrm{RfD}) \\
(\mathrm{mg} /(\mathrm{kg} \cdot \mathrm{d}))\end{array}$ \\
\hline o-xylene & 0.2 \\
m-xylene & 0.2 \\
p-xylene & 0.2 \\
\hline
\end{tabular}

The health risk of non-cancerogen was evaluated by Target hazard quotients (THQ). In general, the health risk was unacceptable when THQ was greater than 1, as below Eq.3.

$$
\mathrm{THQ}=\frac{A D D}{R f D}
$$

Where:

ADD is average daily exposure dose of hazardous substances, $\mathrm{mg} /(\mathrm{kg} \cdot \mathrm{d}) \quad$;

$\mathrm{RfD}$ is reference dose in one exposure route of hazardous substances, $\mathrm{mg} /(\mathrm{kg} \cdot \mathrm{d})$.

\subsubsection{Risk assessment}

1) Usage mass (m)

Through questionnaire survey in 300 primary and secondary students, it take about 1 4 weeks to run out of 1 bottle of correction fluids in 35.2\% students. And it take about $1 \sim 3$ months to run out of 1 bottle of correction fluids, hence, average usage time was supposed to 1 month. The common specification of correction fluid was $15 \mathrm{~g}$ per bottle, that is, the usage mass $\mathrm{m}=15 / 30=0.5 \mathrm{~g} / \mathrm{d}=$ $0.0005 \mathrm{~kg} / \mathrm{d}$.

2) Volume of compounds (V)

The concentration distribution of xylene was not even, when it was released from correction fluids, and the concentration of xylene was decreased by distance increased. The distance of student's nose to correction fluids outlet was $15 \sim 25 \mathrm{~cm}$. The volume of diffusion and response was set the hemisphere space within double distance radius (30 50 cm, set $40 \mathrm{~cm})$, and it was supposed that the concentration of xylene was even, that is, the volume is $0.13 \mathrm{~m}^{3}\left(\mathrm{~V}=2 / 3^{*} \pi^{*} 0.4^{3}=0.13 \mathrm{~m}^{3}\right)$.

3) Daily exposure time (t)

Through questionnaire survey in 300 primary and secondary students, $25.2 \%$ of students spent 30 min to do homework, 39.8\% of students spent 1 hour, $25.4 \%$ of students spent 2 hours and the other spent 3 hours. The exposure time was set to $2 \mathrm{~h}$ in this research, that is, $\mathrm{t}=2 \mathrm{~h} / \mathrm{d}$.

4) Body weight (BW) and Respiration rate (IR)

According to <Exposure Factor Handbook of Chinese Population (Children) >, it was calculated 
short term respiratory volume of $0 \sim 18$-year-old children. The respiration rate of $6 \sim 9,9 \sim 12,12 \sim 15$, and $16 \sim 18$ years old was $0.294 \mathrm{~m}^{3} / \mathrm{h}, 0.384 \mathrm{~m}^{3} / \mathrm{h}, 0.386 \mathrm{~m}^{3} / \mathrm{h}$, and $0.432 \mathrm{~m}^{3} / \mathrm{h}$, respectively. In addition, the Chinese children body weight was as Tab.3.

Tab.3 Recommended value of Chinese children respiration rate and body weight

\begin{tabular}{c|cc}
\hline Age $($ year $)$ & Respiration rate $\left(\mathrm{m}^{3} / \mathrm{h}\right)$ & Average body weight $(\mathrm{kg})$ \\
\hline $6 \sim<9$ & 0.294 & 26.5 \\
$9 \sim<12$ & 0.348 & 36.8 \\
$12 \sim<15$ & 0.396 & 47.3 \\
$15 \sim<18$ & 0.432 & 54.8
\end{tabular}

According to Eq.2 and Eq.3, it was calculated daily exposure dose (ADD) and target hazard quotients (THQ) of xylene exposure from correction fluids as below Tab.4 and Tab.5, respectively.

Tab.4 Daily exposure time (ADD) of xylene in all age of students

\begin{tabular}{|c|c|c|c|c|c|c|c|c|c|c|c|c|}
\hline \multirow{3}{*}{ Brands } & \multicolumn{12}{|c|}{ Daily exposure time $(A D D)$ of xylene $(\mathrm{mg} /(\mathrm{kg} \cdot \mathrm{d}))$} \\
\hline & \multicolumn{4}{|c|}{ o-xylene } & \multicolumn{4}{|c|}{ m-xylene } & \multicolumn{4}{|c|}{ p-xylene } \\
\hline & $6 \sim 9$ & $9 \sim 12$ & $12 \sim 15$ & $15 \sim 18$ & $6 \sim 9$ & $9 \sim 12$ & $12 \sim 15$ & $15 \sim 18$ & $6 \sim 9$ & $9 \sim 12$ & $12 \sim 15$ & $15 \sim 18$ \\
\hline$\# 1$ & 0.37 & 0.32 & 0.28 & 0.26 & 0.78 & 0.66 & 0.59 & 0.55 & 0.42 & 0.36 & 0.32 & 0.30 \\
\hline$\# 2$ & 0.36 & 0.31 & 0.27 & 0.26 & 0.85 & 0.73 & 0.64 & 0.61 & 0.51 & 0.44 & 0.39 & 0.37 \\
\hline \#3 & 1.01 & 0.86 & 0.76 & 0.72 & 2.02 & 1.72 & 1.53 & 1.44 & 1.07 & 0.91 & 0.80 & 0.76 \\
\hline
\end{tabular}

Tab.5 Target hazard quotients (THQ) of xylene in all age of students

\begin{tabular}{|c|c|c|c|c|c|c|c|c|c|c|c|c|}
\hline \multirow{3}{*}{ Brands } & \multicolumn{12}{|c|}{ Target hazard quotients (THQ) of xylene } \\
\hline & \multicolumn{4}{|c|}{ o-xylene } & \multicolumn{4}{|c|}{ m-xylene } & \multicolumn{4}{|c|}{ p-xylene } \\
\hline & $6 \sim 9$ & $9 \sim 12$ & $12 \sim 15$ & $15 \sim 18$ & $6 \sim 9$ & $9 \sim 12$ & $12 \sim 15$ & $15 \sim 18$ & $6 \sim 9$ & $9 \sim 12$ & $12 \sim 15$ & $15 \sim 18$ \\
\hline$\# 1$ & 1.85 & 1.60 & 1.40 & 1.30 & 3.90 & 3.30 & 2.95 & 2.75 & 2.10 & 1.80 & 1.60 & 1.50 \\
\hline$\# 2$ & 1.80 & 1.55 & 1.35 & 1.30 & 4.25 & 3.65 & 3.20 & 3.05 & 2.55 & 2.20 & 1.95 & 1.85 \\
\hline \#3 & 5.05 & 4.30 & 3.80 & 3.60 & 10.1 & 8.60 & 7.65 & 7.20 & 5.35 & 4.55 & 4.00 & 3.80 \\
\hline
\end{tabular}

It indicated that correction fluids production had potential health risk, because the target hazard quotients (THQ) of o-xylene, m-xylene and p-xylene in 3 brands of correction fluids were greater than 1 as shown in Tab.5. In the scene of same exposure duration, different ages' daily exposure dose had some difference due to the difference of respiration rate and body weight, that is, the exposure dose was decrease with age. Therefore, it indicated that the hazardous substances had a far greater impact on the low aged students.

\section{Conclusion}

The research was detected 10 brands of 200 samples, and the result was indicated that xylene content in 3 of brands of correction fluids were exceed reference limits. To established risk assessment model of 3 brands of correction fluids, it was evaluated risk exposure dose of xylene (3 isomers) in correction by respiration exposure and calculated target hazard quotients (THQ). The result was indicated that the correction fluids production had potential health risk to students, as the target hazard quotients (THQ) of xylene (3 isomers) in 3 brands of correction fluids were greater than 1.

The results was suggested that relevant production enterprises improved the quality of products, and selected other less harmful solvent to guarantee the quality of chemical safety in scope of correction fluids usage. Moreover, relevant government department should formulate limit standards, and strengthened random inspection of product quality.

\section{References}

[1] Baidu Encyclopedia. Correction Fluids. http://baike.baidu.com/view/354346.html. [2012-3-27]. 
[2] China Standardization Administration. GB 21027-2007<Request in common use of security for student's articles $>$ [S]. Standards Press of China.2007

[3] China National Development and Reform Commission. QB/T 2655-2004<Correction Fluids>[S]. China Light Industry Press. 2004

[4] Ministry of Industry and Information Technology of the People's Republic of China. QB/T 4154-2010<Correction tape $>$ [S]. China Light Industry Press. 2010

[5] China Ministry of Environmental Protection. <Exposure Factor Handbook of Chinese Population (Children) $>$ [M]. China Environment Publishing Group.2016

[6] US EPA Mercury Study Report to Congress Health Effects of Mercury and Mercury Compounds. Vol V. Washington (DC): United States Environmental Protection Agency.EPA-452/R-97-007. 